\title{
Biomedical engineering education development in China: introduction of BME program in Zhejiang University
}

Xiaoxiang Zheng, Shunren Xia

Xiaoxiang Zheng, Shunren Xia, "Biomedical engineering education development in China: introduction of BME program in Zhejiang University," Proc. SPIE 4588, Seventh International Conference on Education and Training in Optics and Photonics, (28 May 2002); doi: 10.1117/12.468697

SPIE Event: Education and Training in Optics and Photonics 2001, 2001, Singapore, Singapore 
Invited Paper

\title{
Biomedical Engineering Education Development in China -Introduction of BME Program in Zhejiang University
}

\author{
Xiaoxiang Zheng ${ }^{*}$, Shunren Xia** \\ College of Biomedical Engineering \& Instrument Science, Zhejiang University
}

\begin{abstract}
Biomedical engineering is a newly developed interdisciplinary subject developed from the combination of modern life science, medical science and engineering. In this paper, the development of BME program in China is simply dealt with at first, and then BME program in Zhejiang University is presented, especially some effective and innovative acts which have been tested and proved in the process of education and training of undergraduates are emphatically introduced. A conclusion is reached at the end of this paper.
\end{abstract}

Keywords: Biomedical Engineering (BME) Program, education and training, Curriculum, methodology

\section{INTRODUCTION}

BME is a discipline which applies electrical, mechanical, chemical, optical and other engineering principles to understand, modify, or control biologic (i. e. human and animal) system, as well as design and manufacture products that can monitor physiologic functions and assist in the diagnosis and treatment of patients. Therefore, BME is an interdisciplinary or multidisciplinary branch of engineering developed interdisciplinary subject developed from the combination of modern life science, medical science and engineering, which is just like optics and photonics. The research and education field of BME includes :

-Application of engineering system analysis (physiologic modeling, simulation and control) to biologic problems

-Detection, measurement, and monitoring of physiologic signals ( i.e., biosensors and biomedical instrumentation)

-Diagnostic interpretation via signal-processing techniques of bioelectric data

- Therapeutic and rehabilitation procedures and devices (rehabilitation engineering)

- Devices for replacement or augmentation of bodily function (artificial organs)

- Computer analysis of patient-related data and clinical decision-making (i.e., medical informatics and artificial intelligence)

-Medical Imaging, i. e., the graphic display of anatomical detail or physiologic function

-The creation of new biologic products (i. e. Biotechnology and tissue engineering)

-Others

The sketch map of BME research and education areas can be delineated as Fig. 1. As for BME research and education, they can be conducted at system or organ or cell or molecular level.

Many scientists believe that $21^{\text {st }}$ century will be the era of life science, whereas biomedical engineering is the basis and support of life science. Thus we are sure that the biomedical engineering education challenges for the future will become a reality! 


\section{BME PROGRAM IN CHINA}

The biomedical engineering program in China was initially developed in Zhejiang University of China in 1977 . Then a

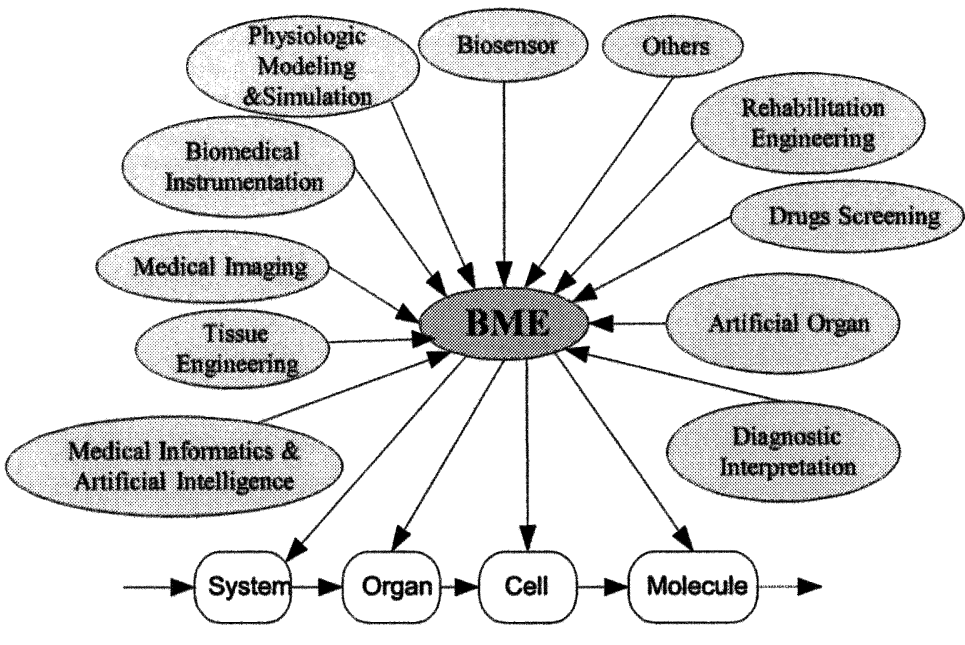

Figure 1: Sketch map of BME areas lot of universities set up BME program in succession under different department or college. Now there are more than 20 established BME program in China, such as Xi'an Jiaotong University, Shanghai Jiaotong University, Tianjin University, Southeast university, Tsinghua University, University of Science and Technology of China, Huazhong University of Science \& Technology, etc. The distribution of principal BME program in China can be found in the following map in detail. Most BME programs were included in comprehensive universities or engineering

universities, whereas others belong to medical universities. Recently, many universities in China undergo the reorganization in order to speed up the interdisciplinary development (BME discipline is an example) and share the high-quality faculties and excellent equipment. The distribution of current BME program in China can be seen in Fig. 2.

In 1984, China created Biomedical Engineering Guidance Committee and drafted BME student's culture goal and main educational aspect in order that the student in BME can master basic knowledge of life science, electronic technology, information and computer science.

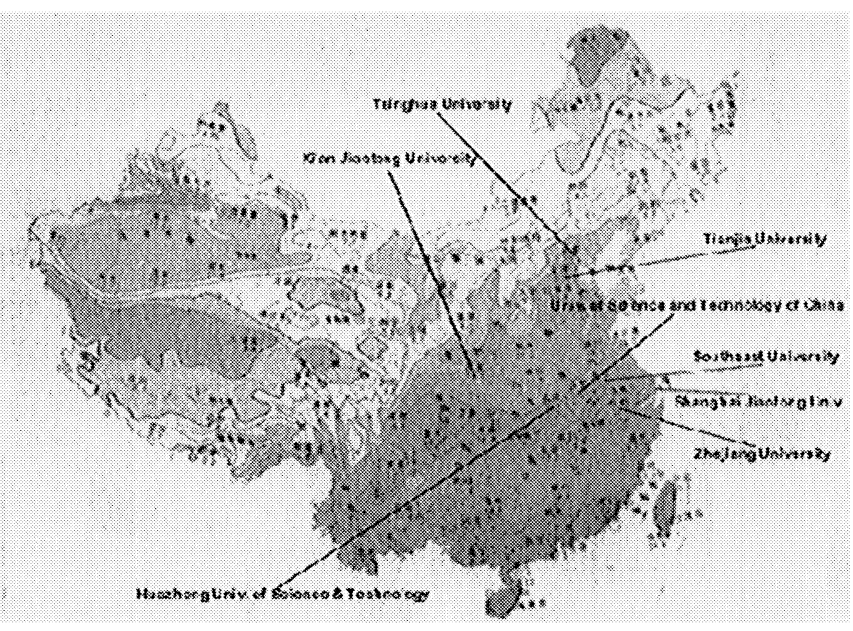

Figure 2: The Distribution of BME program in China

\section{BME PROGRAM IN ZHEJIANG UNIVERSITY}

In the past two decades years, some effective acts for Education \& Training have been summed up, which are listed in the subsections.

\subsection{Perform Modularized Curriculum \& Grading Teaching}

The subjects of study for the undergraduate in BME program are classified under 3 categories, namely

(a) Compulsory subjects: These are required subjects to satisfy graduation requirements. 
(b) Specialized Electives: These are selective subjects prescribed or offered by BME program

(c) General Electives: these are selective subjects prescribed or offered by university

As for electives, every student can choose them on their own to broaden their learning experience and knowledge field.

The subjects of study for the undergraduate in BME program are also being divided into different modules, which are displayed in Fig. 3. While the relationship between the modules and their corresponding subjects is listed in the following Tab.1

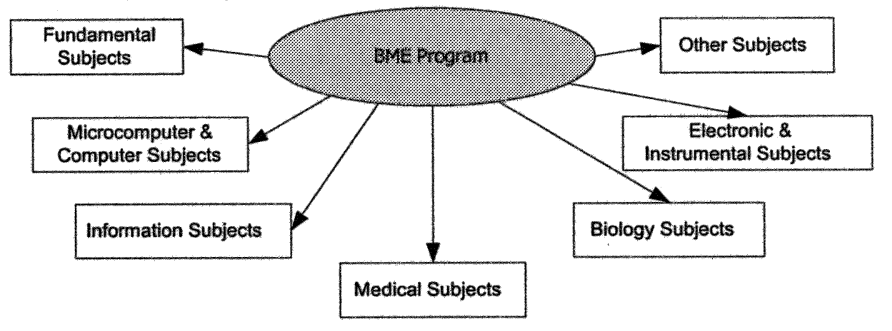

Figure 3: The modules of BME program

Table 1: The relationship between the modules and their corresponding subjects

\begin{tabular}{|c|c|}
\hline Fundamental Subjects & $\begin{array}{l}\text { College English, Computer Basis, Computer Language Programming, Calculus, } \\
\text { Linear Algebra, Physics, Inorganic \& Analytical Chemistry, Organic Chemistry: } \\
\text { Differential Equations, Probability and Statistics, Integral Transform }\end{array}$ \\
\hline $\begin{array}{c}\text { Electronic \& Instrumental } \\
\text { Subjects }\end{array}$ & $\begin{array}{l}\text { Electronic Circuit Theory. Fundamental of Electronic Technology, Transducer } \\
\text { Principle, Electrical Circuit Design \& Practice , Modern Biomedical Devices \& } \\
\text { Equipment. }\end{array}$ \\
\hline $\begin{array}{l}\text { Microcomputer \& } \\
\text { Single-Chip Computer } \\
\text { Subjects }\end{array}$ & $\begin{array}{l}\text { Computer Basis, Computer Programming, Design of Window's Program, } \\
\text { Introduction to Software Engineering, Single-chip Minicomputer Theory, } \\
\text { Microprocessor and lts Application on BME, Introduction to Database, Introduction } \\
\text { to Multimedia, Networks \& Communications }\end{array}$ \\
\hline Med & Engineering Physiology, Quantitative Physiology \\
\hline Information Subjects & $\begin{array}{l}\text { Automatic Control Theory, Digital Signal Processing, Medical Imaging \& Image } \\
\text { Processing, Signal Detecting Technique }\end{array}$ \\
\hline Biology Subjects & General Biology, Cellular Biology, Molecular Biology, Biochemistry \\
\hline ther Subjects & $\begin{array}{l}\text { Introduction to BME, Theoretical Mechanics, Medical Materials \& Artificial } \\
\text { Organs }\end{array}$ \\
\hline
\end{tabular}

With the modularized curriculum and the prior approval of director concerned, the undergraduates can take different combined modules according to their interest and specialty. In addition, BME program in Zhejiang University divided the undergraduate program into two models: one is partial to electronic information, another emphasizes particularly on biology and Chemistry. Besides the common compulsory courses, the former will study these courses systematically, such as digital image processing, the principle of biosensors, theoretical mechanics, introduction to modern medical devices, etc., the latter will prefer to general biology, cellular biology, molecular biology and biochemistry, etc. The purpose of this act is to bring up a lot of talents with different backgrounds.

Besides this, some other opportunities are provided for the undergraduates, such as grading teaching (College English is an example) on the basis of their current level, minor in other programs, etc. 


\subsection{Carry out Academic Credit System}

In Zhejiang University, there are three semesters in each academic year, two normal semesters (18 weeks) and one short semester (4 weeks)(Tab. 2)

Table 2: Academic Calendar (For Undergraduate Students)

\begin{tabular}{|l|c|}
\hline \multicolumn{2}{|c|}{ 2001-2002 Academic Year } \\
\hline Semester 1 & 24 Sep. 2001- 27 Jan. 2002 (18 Weeks) \\
\hline Winter Vacation & 27 Jan. 2002- 23 Feb. 2002 (4 Weeks) \\
\hline Semester 2 & 24 Feb. 2002- 7 Jul. 2002 (18 Weeks) \\
\hline Short Semester & 8 Jul. 2002- 4 Aug. 2002 (4 Weeks) \\
\hline Summer Vacation & 5 Aug. 2002- 23 Sep. 2001 (7 Weeks) \\
\hline
\end{tabular}

Under the Academic Credit(AC) System, each subject is assigned a certain number of academic credits,

For a typical one-semester subject, the number of academic credits is calculated as follows:

One hour of lecture per week: $1 \mathrm{AC}$

2 Hours' laboratory per week: $1 \mathrm{AC}$

The practical activities in the short semester has durations and number of $\mathrm{AC}$ as follows (Tab. 3):

Table 3: The relationship between program items and duration and ACs

\begin{tabular}{|l|l|l|}
\hline Program & Duration & ACs \\
\hline Computer programming & 4 weeks & 3 \\
\hline Production practice & 4 weeks & 3 \\
\hline Clinical practice & 4 weeks & 3 \\
\hline
\end{tabular}

To be eligible for the award of a Bachelor's degree of BME program, a student must fulfill the following conditions:

(a)Complete no less than 190.5 ACs, including no less than 160.5 ACs compulsory subjects, no less than 10 ACs general electives and no less than $20 \mathrm{ACs}$ specialized electives.

(b)Pass all examinations prescribed by the statute governing the degree.

(c)Satisfy all other requirements prescribed by the statute governing the degree.

Under AC system, excellent students can have more extensive space for their selection, they can graduate ahead of specified schedule (Normal period of candidature is 5 years)and pursue further study of higher degree.

\subsection{Create More Practice Activities}

Some practical activities are listed below:

-Set up some special unattached experiment subjects, independent of theoretical subjects, such as electronic design and practice $(4$ ACs).

-Practical activities in three short semesters, that is to say, Computer programming, Production practice and Clinical practice - Construct the undergraduate electronic repairing group (Fig. 4.)

-Last year's project or diploma work (nearly last one year)

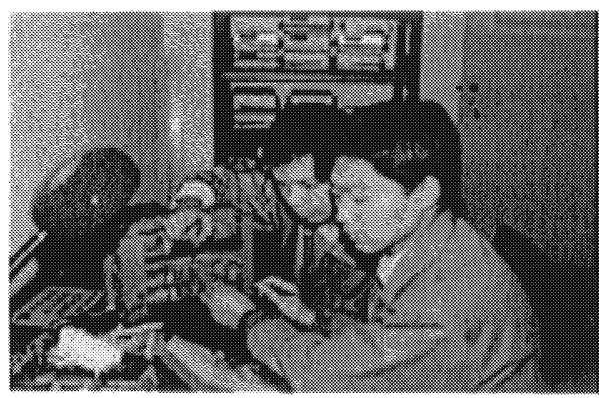

Figure 4: The Undergraduates are repairing the equipment

\subsection{Put Student Research Training Program (SRTP) into Practice}


Student Research Training Program (SRTP) is a program set up by Zhejiang University, under which staffs or students can set up research projects and apply for some financial supports to do some approved research work with the purpose of enhancing the student's research ability and training the student's intelligence and creativity. The number of projects on SRTP set by staffs or students is listed below (Tab.4 ). We can find that the number of SRTP program set by the students is increasing year after year.

Table 4: The number of SRTP set by the Staff and Student ${ }^{2}$

\begin{tabular}{|c|c|c|c|c|}
\hline \multirow{2}{*}{ Duration of Year } & \multicolumn{2}{|c|}{ Totality(Zhejiang University) } & \multicolumn{2}{|c|}{ BME program } \\
\cline { 2 - 5 } & Staff & Student & Staff & Student \\
\hline $1999-2000$ & 139 & 71 & 6 & 3 \\
\hline $2000-2001$ & 196 & 188 & 3 & 3 \\
\hline $2001-2002$ & 154 & 283 & 3 & 3 \\
\hline
\end{tabular}

\subsection{Adopt up-to-date and High-Quality Textbooks \& References}

Nowadays, knowledge is updated and expanded rapidly, therefore the textbooks or reference books used by the staffs and students must keep pace with the times. Staffs are encouraged to apply the up-to-date and high-quality books in the BME program, especially the latest references in English.

By doing this, once the students graduate from the university, the knowledge and skills they have mastered will not lag behind the times.

\subsection{Apply Modern Teaching Methodology}

Besides other factors described above, teaching methodology plays an important role during the process of education. A few years ago, its importance was recognized, and some modern and effective methods were applied into teaching such as,

- Applying modern teaching facilities. There are slide projector, OHP and computer projector or videoconference system in many lecture theatres;

- Increasing the self-study and Intra-discussion subjects to culture students' thinking capacity and communication atmosphere;

- Adopting Web-based multimedia computer assisted instruction (MCAI) courseware (Engineering Physiology, DSP, MIP, etc.);

- Others.

Fig. 5 is only an example of the appearance of the web-based computer assisted instruction courseware for medical image processing and digital signal processing developed by the staff of BME program. With such methods, we can train student's self-study ability, change student's studying passivity in the classroom into activity.

\subsection{Develop Different Kinds of Competitions \& Activities}

Many kinds of competitions in which students can participate are listed below:

-International Mathematic Modeling Contest

-Electronic Design Competition(National, Zhejiang Provincial and ZJU)

- "Grasp the Future" science and technology intelligence competition

-National "Challenge Cup"-The "Silicon Valley in Paradise" college student career design competition

-Campus landscape designing competition 
- "My University, My Web Site" web site designing competition

-Others.
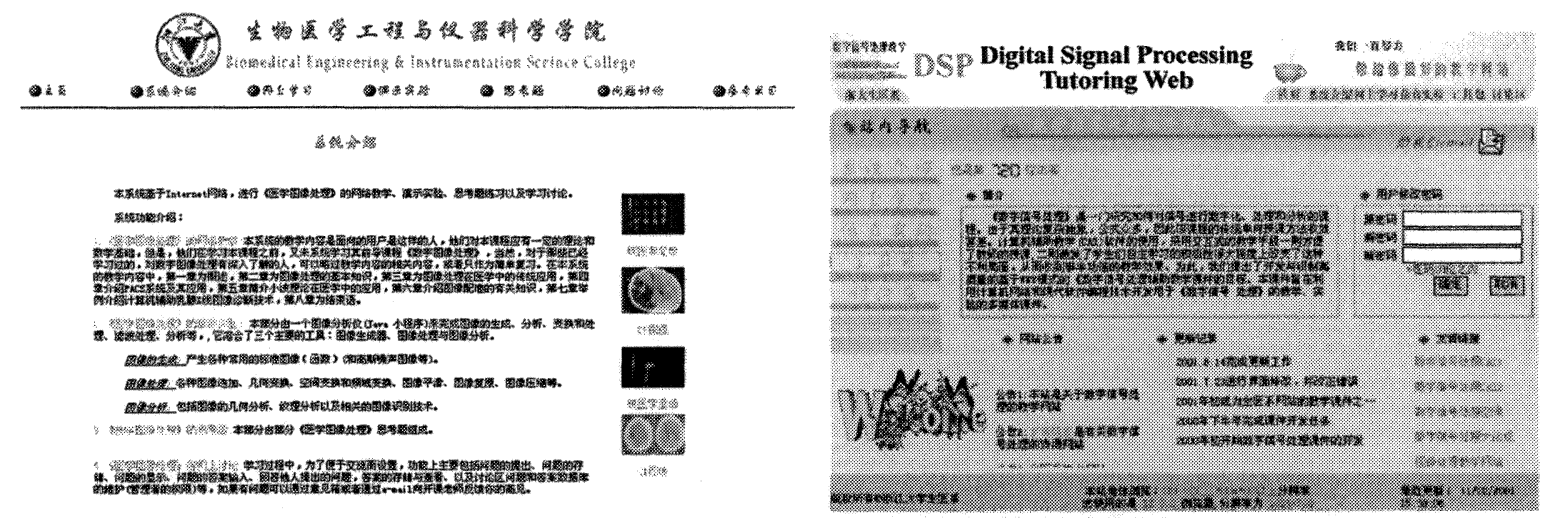

Figure 5: The Web-based computer assisted instruction courseware for Medical Image Processing and

Digital Signal Processing separately

Especially, International Mathematic Modeling Contest is now regarded as important criteria for college students' innovating abilities, practical capability and comprehensive qualities. In 2001, all 6 teams of Zhejiang University won the first prizes in the Contest. This is the best achievement for Zhejiang University in this kind of international contests for 3 years in succession since 1999.

All these competitions \& activities provide a broad stage for students to show their innovative abilities as well a good chance for them to communicate with each other.

These academic activities have not only built up a strong academic atmosphere in the university, but also attracted many risk investment. Up till now, many of the students in Zhejiang University have got patents for their scientific achievements, and some have even started their undertaking.

\subsection{Strengthen Interuniversity Exchanges}

Zhejiang University and its subsidiary schools and departments have established academic ties with more than 100 universities and their subsidiary departments in over 26 countries and regions. As for BME program, an agreement for co-training the undergraduates between Drexel University, The Chinese University of Hong Kong, Zhejiang University and Shanghai Jiaotong University has been also signed in 2000.

With these formal relationships, the university has put into operation various cooperative programs and projects, such as student and scholar exchanges, international conferences and symposiums, joint research and joint postgraduate tutoring.

\section{CONCLUSION}

Indeed, the issue of education and training has been paid educator's high attention to today. At the Whitaker Foundation Biomedical Engineering Educational Summit Workshop in 2000, Participants in the workshop came up with dozens of suggestions for what should be included in future curricula for real-world BME experiences, such as ${ }^{3}$,

1. Restructure as many courses as possible so that they use a problem-based learning approach.

2.Teach design courses throughout the curriculum if resources allow that. Otherwise, integrate design into existing 
engineering and science courses by having students do design-related projects.

3. Provide students with a wide array of real world experiences, including guest instructors with expertise outside the classroom (e.g., physicians), lab courses, lab research, clinical-rotation courses, independent study, field experience (industrial internship), team and individual work, career counseling, workshops, which include team work, guest lectures and research (can be three days long, five per course), case studies, multiple instructors for one course, partnerships between engineering and business students

4. Impart and require comprehensive communication skills, including:

. How to write a memo, a technical report, a business plan and a grant proposal

. How to communicate with other professionals (e.g., lawyers, physicians), laypeople and children

. Interpersonal skills

. Oral-presentation skills

5. Consider giving freshmen a real world experience, even though real world problems can be very complex. Freshmen could be required to do a clinical rotation, which they usually find thrilling even if they do not understand everything. Many students leave BME because the first couple of years are so boring.

6. Consider different approaches for undergraduate and graduate curriculum redesign. The same subject can be taught at different levels. Graduate education should involve more in-depth knowledge. Industry expects different things from undergraduate and graduate students.

7. Take into account ABET requirements during the curriculum-redesign process.

8. Develop quantitative assessment tools for every subject, skill area and approach.

As biomedical engineering is an important basis and dynamics of medical science and biology, the higher education in China must face the whole world, the future, and the modernization, and it's the time to set up advanced education theory and to keep up with the trend of global educational development.

\section{REFERENCES}

1. Joseph D. Bronzino, The Biomedical Engineering Handbook, CRC Press LLC, 2000.

2. Guide to Student's Research Training Program, Zhejiang University, 1999-2001.

3. The Whitaker Foundation Biomedical Engineering Educational Summit Workshop Summary, Lansdowne, VA, USA, December 7-10, 2000

* zxx@mail.hz.zi.cn; phone 86571 87951091; fax 86571 87951676; http://www.zju.edu.cn; College of Biomedical Engineering \& Instrument Science, Zhejiang University, 310027, Hangzhou, China; **shunrenxia@263.net; phone 8657187951703 ; fax 86571 87951676; http://www.zju.edu.cn; Department of Biomedical Engineering, Zhejiang University, 310027, Hangzhou, China 